\title{
НЕОНАТАЛЬНЫЕ СУДОРОГИ У ДЕТЕЙ РАЗЛИЧНОГО ГЕСТАЦИОННОГО ВОЗРАСТА
}

\author{
*Заваденко А.Н., Медведев М.И., Дегтярева М.Г., Рогаткин С.О., Заваденко Н.Н. \\ Российский Национальный Исследовательский Медицинский Университет им. Н.И. Пирогова \\ Минздрава России, Москва, РФ
}

\begin{abstract}
Ведущие этиологические факторы неонатальных судорог (НC) изучались у новорожденных, которые были распределены на группы в зависимости от гестационного возраста (ГВ): I - 84 глубоко недоношенные с ГВ 28 нед. и менее, II - 52 с ГВ 29-32 нед., III - 12 с ГВ 33-36 нед., IV - 17 доношенные с ГВ 37-41 нед. Клинико-инструментальное обследование всех 165 пациентов определило следующие причины НС: 72,1\% - церебральная гипоксия-ишемия; 6,1\% пери-интравентрикулярные кровоизлияния (ПИВК) III/IV степени; 9,7\% - внутриутробные инфекции с поражением ЦНС; 9,7\% - нейроинфекции; 1,2\% - церебральные дисгенезии; 1,2\% - генетические заболевания. При этом ПИВК IIIIV ст. как причина НС отмечались только у недоношенных с ГВ до 32 нед. Среди доношенных увеличивалась роль нейроинфекций $(23,5 \%)$. При обследовании детей с НС следует учитывать вероятность генетических заболеваний, прежде всего, при отсутствии очевидных причин раннего поражения ЦНС. Это важно, поскольку что в настоящее время возрастают возможности таргетной терапии при эпилептических синдромах генетической природы. Рассматриваются перспективы применения леветирацетама у детей с НС и ранними формами эпилепсии.

Ключевые слова: неонатальные судороги, недоношенные новорожденные, доношенные новорожденные, эпилепсия, эпилептические энцефалопатии, леветирацетам.
\end{abstract}

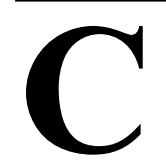

удороги новорожденных или неонатальные судороги (НС) находятся в центре внимания как детских неврологов, так и специалистов перинатальной медицины $[1,2]$. Риск развития судорог у детей первого месяца жизни выше, чем в любом другом возрастном периоде. При этом риск НС тем выше, чем меньше гестационный возраст (ГВ) и ниже масса тела ребенка при рождении [2,3]. В целом НС встречаются у 3-5 из 1000 новорожденных, но среди доношенных детей у 2-3 на 1000, а недоношенных - у 10-15 на 1000 [4].

В отличие от приступов судорог у детей, более старших возрастных групп, НС имеют особые клинические и электроэнцефалографические характеристики, этиологические факторы и подходы к терапии. Подавляющее большинство НС являются острыми симптоматическими вследствие церебрального повреждения или дисфункции, и их возникновение зачастую служит ранним маркером основного заболевания, которое может потребовать специфической терапии [3].

Значительная частота судорог у новорожденных и младенцев обусловлена морфо-функциональными особенностями развивающегося головного мозга, определяющими высокую степень судорожной реактивности. Подверженность приступам незрелого мозга новорожден- ных высока в связи с преобладанием нейротрансмиссии возбуждающего характера, ионным дисбалансом, деполяризующими/возбуждающими эффектами ГАМК, несформированностью механизмов ингибирования и межклеточных связей, незавершенностью процессов миелинизации и синаптогенеза $[3,5]$. Причинами НС могут быть не только различные повреждения ЦНС, но и другие факторы: метаболические, инфекционные, токсические [6]. В ряде случаев НС являются первым проявлением эпилепсии.

Этиология НС - ключевой фактор, определяющий прогноз. Катамнестические исследования новорожденных с острыми симптоматическими НС показывают, что частота развития тяжелой патологии, включая эпилепсию, церебральные параличи, нарушения интеллектуального и психоречевого развития или их сочетание, оказывается во много раз выше, чем в группах детей без судорог [2,3,7]. По данным метаанализа 44 исследований, проведенных с 1954 по 2013 год, эпилепсия развилась у 17,9\% пациентов с НС, из них уже на первом году жизни у $68,5 \%$ [8]. В ходе динамического наблюдения эпилепсия в качестве единственного заболевания отмечалась у 19,3\% пациентов, а у 80,7\% сопровождалась другими неврологическими нарушениями: снижением интеллекта - у 18\%,

*e-mail: aleks.zavadenko@gmail.com 
церебральным параличом - у 6,1\%, одновременно интеллектуальными расстройствами и церебральным параличом - у 44,8\% [8].

Цель исследования: определить основные этиологические факторы и клинические особенности НС в группах новорожденных детей различного ГВ.

Материалы и методы исследования. Обследовано 165 детей (88 мальчиков, 77 девочек), перенесших НC, рожденных на сроке гестации 22-41 нед., с массой тела при рождении от 450 до 4040 г. Среди них 31 (18,8\%) были из двоен, $5(3,0 \%)$ - из троен, $4(2,4 \%)$ - из четверни.

Продолжительность катамнестического наблюдения за детьми составила 2-5 лет. Критерий включения в исследование: наличие клинических НC в первые 28 дней жизни для доношенных детей и до 44 недели постменструального возраста для недоношенных. В исследование были включены только новорожденные с верифицированными НС, которые фиксировались при клиническом осмотре и/или проведении видео-ЭЭГ- мониторинга, либо на основании подробных описаний НС неврологом в истории болезни.

К критериям исключения были отнесены пиридоксин-зависимые приступы и транзиторные метаболические нарушения (гипогликемия, гипокальциемия, гипомагниемия, гипер- и гипонатриемия).

Основным группирующим признаком был ГВ детей. Сформированы 4 группы сравнения: I 84 глубоко недоношенные новорожденные с ГВ 28 нед. и менее, II - 52 ребенка с ГВ 29-32 нед., III - 12 детей с ГВ 33-36 нед. и IV - 17 доношенные новорожденные с ГВ 37-41 нед. Распределение детей в группах сравнения по полу, массе тела при рождении и тяжести перинатального поражения (ПП) ЦНС показано в таблице 1. Группы сравнения имели статистически значимые отличия по основным антропометрическим показателям при рождении, обусловленные ГВ. Более подробная характеристика обследованных пациентов представлена в предыдущих публикациях $[9,10]$.

Таблица 1

Характеристика групп обследованных пациентов

\begin{tabular}{|c|c|c|c|c|c|c|c|c|c|}
\hline \multirow{2}{*}{\multicolumn{2}{|c|}{ Группы пациентов }} & \multicolumn{2}{|c|}{$\begin{array}{c}\text { I группа } \\
\text { ГВ } \leq 28 \\
\text { нед., } n=84\end{array}$} & \multicolumn{2}{|c|}{$\begin{array}{c}\text { II группа } \\
\text { ГВ 29-32 } \\
\text { нед., n=52 }\end{array}$} & \multicolumn{2}{|c|}{$\begin{array}{c}\text { III группа } \\
\text { ГВ 33-36 } \\
\text { нед., n=12 }\end{array}$} & \multicolumn{2}{|c|}{$\begin{array}{c}\text { IV группа } \\
\text { ГВ 37-41 } \\
\text { нед., n=17 }\end{array}$} \\
\hline & & $\mathbf{n}$ & $\%$ & $\mathbf{n}$ & $\%$ & $\mathbf{n}$ & $\%$ & $\mathbf{n}$ & $\%$ \\
\hline Пол & М / Ж & $42 / 42$ & $\begin{array}{c}50 / \\
50\end{array}$ & $29 / 23$ & $56 / 44$ & $7 / 5$ & $58 / 42$ & $10 / 7$ & $59 / 41$ \\
\hline $\begin{array}{l}\text { Масса тела } \\
\text { при } \\
\text { рождении, г }\end{array}$ & $\begin{array}{l}\text { Медиана } \\
\text { (диапазон) }\end{array}$ & \multicolumn{2}{|c|}{$\begin{array}{c}930 \\
(450-1580)\end{array}$} & \multicolumn{2}{|c|}{$\begin{array}{c}1420 \\
(690-1950)\end{array}$} & \multicolumn{2}{|c|}{$\begin{array}{c}2160 \\
(1370-2730)\end{array}$} & \multicolumn{2}{|c|}{$\begin{array}{c}3600 \\
(2590-4040)\end{array}$} \\
\hline \multicolumn{2}{|c|}{$\begin{array}{l}\text { ПП ЦНС средней степени } \\
\text { тяжести }\end{array}$} & 34 & 40 & 24 & 46 & 6 & 50 & 5 & 29 \\
\hline \multicolumn{2}{|c|}{ ПП ЦНС тяжелой степени } & 50 & 60 & 28 & 54 & 6 & 50 & 12 & 71 \\
\hline
\end{tabular}

Примечание: $n$-обсалютное число

Комплексное клинико-инструментальное обследование детей в стационаре включало анализ анамнестических сведений, оценку соматического статуса, исследование неврологического статуса с применением методов количественных шкал, видео-ЭЭГ-мониторинг, методы нейровизуализации. Оценку тяжести поражения ЦНС проводили в соответствии с Классификацией перинатальных поражений ЦНС Российской ассоциации специалистов перинатальной медицины [11].

Методы нейровизуализации. Всем детям выполнялась нейросонография для объективизации клинических признаков ПП ЦНС и оценки динамики выявленных структурных церебральных повреждений. По показаниям проводились 
КТ, МРТ. Степень ишемических и геморрагических повреждений оценивали согласно Классификации перинатальных поражений ЦНС [11].

Нейрофизиологические методы. Компьютерная многоканальная ЭЭГ с визуальной экспертной оценкой биоэлектрической активности (БЭА) мозга проводилась в режиме мониторинга дневного сна (24-х канальный электроэнцефалограф с опцией видеозаписи «Neurotravel», «Ates Medica Device», Италия), в скорректированном возрасте (СВ) 36-40 нед., 44-46 нед. от зачатия, и 6 мес. Продолжительность регистрации составляла не менее 45 мин. В СВ 36-40 и 44-46 нед. применяли «Типологическую классификацию ЭЭГ-паттернов сна» [12], дополненную характеристиками онтогенетических маркеров созревания БЭА [13].

Статистическая обработка результатов. Использовался пакет программ «Statistica 8.0». Применялись методы непараметрической статистики, статистически значимыми считались различия при значениях критерия $\mathrm{p}<0,05$.

Результаты. По результатам клиникоинструментального обследования всех пациентов $(\mathrm{n}=165)$ ведущими в этиологии НС явились шесть факторов:

1. $72,1 \%$ (119 пациентов) - перинатальная церебральная гипоксия-ишемия (гипоксическиишемическая энцефалопатия);

2. 6,1\% (10 пациентов) - пери-интравентрикулярные кровоизлияния (ПИВК) III/IV степени;

3. 9,7\% (16 пациентов) - внутриутробные инфекции с поражением ЦНС;

4. 9,7\% (16 пациентов) - нейроинфекции (вирусные менингоэнцефалиты и бактериальные менингиты);

5. 1,2\% (2 пациента) - церебральные дисгенезии;

6. 1,2\% (2 пациента) - генетические заболевания.

Между тем, в группах обследованных пациентов имелись различия в частоте встречаемости этиологических факторов НС, что могло быть связано с их ГВ (таб. 2).

У детей групп I и II с ГВ менее 32 недель основной причиной НС являлась перинатальная церебральная гипоксия-ишемия: соответственно $70,2 \%$ и $80,8 \%$ случаев. Только в группах I и II были диагностированы ПИВК III/IV степени: $6,0 \%$ и $9,6 \%$ случаев.
У детей групп III и IV (более зрелых) церебральная гипоксия-ишемия также была ведущей причиной НС. В группе III на ее долю приходилось $58,3 \%$, в группе IV - 64,7\% случаев. Хотя частота церебральной гипоксии-ишемии оказалась ниже по сравнению с группами I и II, эти различия не достигали степени статистической значимости. Среди доношенных новорожденных группы IV в отличие от пациентов групп I и II значимо чаще встречались нейроинфекции: $23,5 \%$ в сравнении с $10,7 \%$ и $3,9 \%$.

Внутриутробные инфекции с более высокой частотой выявлены в группах I и III $(13,1 \%$ и $16,7 \%)$, чем в группах II и IV (3,9\% и 5,9\%).

В нашей серии наблюдений относительно редкими причинами НС стали церебральные дисгенезии - $1,2 \%$ случаев, а также генетические заболевания ЦНС (из классов нейродегенераций и болезней обмена) - $1,2 \%$.

Семиология НС. Сочетание различных типов НC (полиморфные НС) наблюдалось у 38,8\% $(\mathrm{n}=64)$ обследованных (таб. 3) и преобладало во всех четырех группах. Судороги в виде моторных, глазодвигательных феноменов или эпилептические неонатальные апноэ (атипичные или стертые, фрагментарные приступы) диагностированы в 29,1\% (n=48) случаев. Клонические приступы отмечались в 16,9\% (n=28) случаях; реже были зарегистрированы судороги миоклонического $(12,1 \%, \mathrm{n}=20)$ и тонического $(3,0 \%$, $\mathrm{n}=5)$ характера. Наличие фокального компонента в структуре полиморфных НС встречалось достаточно редко - в 9,1\% (n=15) случаев.

По сравнению с более зрелыми новорожденными (III и IV группы), для которых были характерны клонические и тонические НC, у детей с ГВ менее 33 нед. (группы I и II) с большей частотой были диагностированы атипичный и миоклонический характер приступов. Фокальные клонические приступы зафиксированы главным образом среди детей с ГВ более 32 нед. (21,4\% случаев). Мультифокальные клонические НС были отмечены преимущественно среди детей с ГВ 32 нед. и менее $(78,6 \%$ случаев). Тонические НС всегда имели генерализованный характер, встречались наиболее редко и чаще регистрировались у более зрелых новорожденных групп III и IV - в 33,3\% и 23,5\% слу- 
Таблица 2

Этиология неонатальных судорог в группах обследованных пациентов

\begin{tabular}{|c|c|c|c|c|c|c|c|c|c|c|}
\hline \multirow[t]{2}{*}{ Группы пациентов } & \multicolumn{2}{|c|}{$\begin{array}{c}\text { I группа } \\
\text { ГВ } \leq 28 \\
\text { нед. } \mathbf{n}=84\end{array}$} & \multicolumn{2}{|c|}{$\begin{array}{c}\text { II группа } \\
\text { ГВ 29-32 } \\
\text { нед., n=52 }\end{array}$} & \multicolumn{2}{|c|}{$\begin{array}{c}\text { III группа } \\
\text { ГВ 33-36 } \\
\text { нед., n=12 }\end{array}$} & \multicolumn{2}{|c|}{$\begin{array}{c}\text { IV группа } \\
\text { ГВ 37-41 } \\
\text { нед., } n=17\end{array}$} & \multicolumn{2}{|c|}{$\begin{array}{l}\text { Всего } \\
\mathrm{n}=165\end{array}$} \\
\hline & $\mathrm{n}$ & $\%$ & $\mathrm{n}$ & $\%$ & $\mathrm{n}$ & $\%$ & $\mathrm{n}$ & $\%$ & $\mathrm{n}$ & $\%$ \\
\hline $\begin{array}{l}\text { Церебральная } \\
\text { гипоксия-ишемия }\end{array}$ & 59 & 70,2 & 42 & 80,8 & 7 & 58,3 & 11 & 64,7 & 119 & 72,1 \\
\hline $\begin{array}{l}\text { ПИВК III/IV } \\
\text { степени }\end{array}$ & 5 & 6,0 & 5 & 9,6 & 0 & 0 & 0 & 0 & 10 & 6,1 \\
\hline $\begin{array}{l}\text { Внутриутробные } \\
\text { инфекции }\end{array}$ & 11 & 13,1 & 2 & 3,9 & 2 & 16,7 & 1 & 5,9 & 16 & 9,7 \\
\hline Нейроинфекции & 9 & 10,7 & 2 & 3,9 & 1 & 8,3 & 4 & 23,5 & 16 & 9,7 \\
\hline $\begin{array}{l}\text { - вирусные } \\
\text { менингоэнцефалиты } \\
\text { - бактериальные }\end{array}$ & 3 & 3,6 & 1 & 1,9 & 1 & 8,3 & 4 & $\begin{array}{l}23,5 * \\
\left(p^{4-1}-1\right. \\
\left.n^{4} 2\right)^{\prime}\end{array}$ & 9 & 5,5 \\
\hline менингиты & 6 & 7,1 & 1 & 1,9 & 0 & 0 & 0 & $\begin{array}{c}\mathrm{p}^{--} \\
0\end{array}$ & 7 & 4,2 \\
\hline $\begin{array}{l}\text { Церебральные } \\
\text { дисгенезии } \\
\text { - порэнцефалия } \\
\text { - микрополигирия и } \\
\text { микроцефалия }\end{array}$ & $\begin{array}{l}0 \\
0 \\
0\end{array}$ & $\begin{array}{l}0 \\
0 \\
0\end{array}$ & $\begin{array}{l}0 \\
1 \\
0\end{array}$ & $\begin{array}{c}0 \\
1,9 \\
0\end{array}$ & $\begin{array}{l}0 \\
0 \\
1\end{array}$ & $\begin{array}{c}0 \\
0 \\
8,3\end{array}$ & $\begin{array}{l}0 \\
0 \\
0\end{array}$ & $\begin{array}{l}0 \\
0 \\
0\end{array}$ & $\begin{array}{l}2 \\
1 \\
1\end{array}$ & $\begin{array}{l}1,2 \\
0,6 \\
0,6\end{array}$ \\
\hline $\begin{array}{l}\text { Генетические } \\
\text { заболевания } \\
\text { - синдром Айкарди- } \\
\text { Гутерье } \\
\text { - гликогеноз Ib типа }\end{array}$ & $\begin{array}{l}0 \\
0 \\
0\end{array}$ & $\begin{array}{l}0 \\
0 \\
0\end{array}$ & $\begin{array}{l}0 \\
0 \\
0\end{array}$ & $\begin{array}{l}0 \\
0 \\
0\end{array}$ & $\begin{array}{l}1 \\
1 \\
0\end{array}$ & $\begin{array}{c}8,3 \\
8,3 \\
0\end{array}$ & $\begin{array}{l}1 \\
0 \\
1\end{array}$ & $\begin{array}{c}5,9 \\
0 \\
5,9\end{array}$ & $\begin{array}{l}2 \\
1 \\
1\end{array}$ & $\begin{array}{l}1,2 \\
0,6 \\
0,6\end{array}$ \\
\hline
\end{tabular}

Примечание: ${ }^{*} p<0,05$

чаях соответственно, по сравнению с детьми групп I и II - 16,7\% и 11,5\%. Фокальный компонент при полиморфных приступах (тоническая девиация глазных яблок, иногда вместе с отведением головы в сторону), наблюдался значимо чаще у детей с более высоким ГВ $\left(\chi^{2}(\mathrm{df}=3)=9,66\right.$, $\mathrm{p}=0,020)$.

Важно отметить, что клинический тип приступов не имел статистически значимой взаимосвязи с характером и этиологией структурного повреждения мозга.

Дебют $\boldsymbol{H C}$ в 37,8\% (n=59) случаев приходился на первые 24 часа жизни. Частота возникновения приступов снижалась до $24,2 \%(\mathrm{n}=40)$ на протяжении 24-72 часов жизни. В период от 72 часов до конца 1-й нед. жизни НС возникали в 3 раза реже по сравнению с первыми сутками и отмечались в $12,7 \%(\mathrm{n}=21)$ случаев. В дальнейшем от 7 дней жизни до СВ 44 нед. частота встречаемости НС возрастала до $27,9 \%(n=46)$. По срокам дебюта НС различия между группами не достигали статистической значимости.

Во всех группах было зарегистрировано значительное снижение случаев НС к концу 1-й недели жизни. В период от 7 дней до СВ 44 нед. увеличение частоты регистрации НС происходило во всех группах, при этом наиболее значимый рост отмечался у пациентов II $(32,7 \%$, $\mathrm{n}=17)$ и IV групп $(29,4 \%, \mathrm{n}=5)$ по сравнению с группами I $(23,8 \%, \mathrm{n}=20)$ и III $(16,7 \%, \mathrm{n}=2)$. 
Клинические типы неонатальных судорог у детей обследованных групп

\begin{tabular}{|c|c|c|c|c|c|c|c|c|c|c|}
\hline \multirow{2}{*}{$\underset{\text { Характер }}{\underset{H C}{ }}$} & \multicolumn{2}{|c|}{$\begin{array}{c}\text { I группа } \\
\text { ГВ } \leq 28 \\
\text { нед., } \\
\text { n=84 }\end{array}$} & \multicolumn{2}{|c|}{$\begin{array}{c}\text { II группа } \\
\text { ГВ 29-32 } \\
\text { нед., } \\
\text { n=52 }\end{array}$} & \multicolumn{2}{|c|}{$\begin{array}{c}\text { III группа } \\
\text { ГВ 33-36 } \\
\text { нед., } \\
\text { n=12 }\end{array}$} & \multicolumn{2}{|c|}{$\begin{array}{c}\text { IV группа } \\
\text { ГВ 37-41 } \\
\text { нед., } \\
\text { n=17 }\end{array}$} & \multicolumn{2}{|c|}{$\begin{array}{l}\text { Всего, } \\
\mathrm{n}=165\end{array}$} \\
\hline & $\mathrm{n}$ & $\%$ & $\mathrm{n}$ & $\%$ & $\mathrm{n}$ & $\%$ & $\mathrm{n}$ & $\%$ & $\mathrm{n}$ & $\%$ \\
\hline Атипичные & 23 & 27,4 & 20 & 38,5 & 2 & 16,7 & 3 & 17,7 & 48 & 29,1 \\
\hline Клонические & 14 & 16,7 & 6 & 11,5 & 4 & 33,3 & 4 & 23,5 & 28 & 16,9 \\
\hline Миоклонические & 15 & 17,9 & 5 & 9,6 & - & - & - & - & 20 & 12,1 \\
\hline Тонические & 1 & 1,2 & 1 & 1,9 & 2 & 16,7 & 1 & 5,9 & 5 & 3,0 \\
\hline $\begin{array}{l}\text { Полиморфные } \\
\text { (сочетание различ- } \\
\text { ных типов НС) }\end{array}$ & 31 & 36,9 & 20 & 38,5 & 4 & 33,3 & 9 & 52,9 & 64 & 38,8 \\
\hline $\begin{array}{l}\text { С фокальным } \\
\text { компонентом }\end{array}$ & 5 & $\begin{array}{l}6,0^{*} \\
\mathrm{p}^{1-3} \\
\mathrm{p}^{1-4}\end{array}$ & 3 & $\begin{array}{l}5,8^{*} \\
\mathrm{p}_{-3}^{2-3} \\
\mathrm{p}^{2-4}\end{array}$ & 3 & 25,0 & 4 & 23,5 & 15 & 9,1 \\
\hline
\end{tabular}

Примечание: *p<0,05

Обсуждение. По данным литературы $[1-3,6]$ причины НС охватывают широкий круг неврологических расстройств. В клинической практике установление этиологии НС исключительно важно для выбора лечебной тактики и оценки прогноза. Так, НС, обусловленные преходящими метаболическими нарушениями неонатального периода (гипокальциемия и гипогликемия), купируются путем коррекции метаболических изменений и обычно характеризуются благоприятными исходами в отношении психомоторного развития и риска эпилепсии. С другой стороны, $\mathrm{HC}$, связанные со структурными изменениями ЦНС, трудно поддаются терапии и ассоциированы с неблагоприятным прогнозом.

В нашу когорту из 165 детей с НС не включались пациенты с приступами, обусловленными преходящими метаболическими нарушениями (гипогликемией, гипокальциемией, гипомагниемией, гипер- и гипонатриемией), и пиридоксинзависимыми приступами. На основании данных комплексного клинико-инструментального обследования у наблюдавшихся нами пациентов были подтверждены следующие причины НС: $72,1 \%$ - церебральная гипоксия-ишемия, 6,1\% ПИВК III/IV степени; 9,7\% - внутриутробные инфекции; 9,7\% - нейроинфекции (вирусные менингоэнцефалиты и бактериальные менингиты); 1,2\% - церебральные дисгенезии; $1,2 \%$ генетические заболевания.

Эти результаты согласуются с современными данными о ведущей роли церебральной гипоксии-ишемии (или перинатальной гипоксическиишемической энцефалопатии) среди причин НС $[2,3,6]$. В условиях нестабильного функционирования системы ауторегуляции церебрального кровотока и ее морфофункциональной незрелости у недоношенных новорожденных отмечается высокая частота гипоксически-ишемических и геморрагических поражений ЦНС на первой неделе постнатальной жизни. Именно в этот период возникает до 85\% всех ПП ЦНС у недоношенных детей [3].

Довольно редкими причинами НС в нашей когорте пациентов оказались церебральные дисгенезии $(1,2 \%)$ и генетические заболевания ЦНС $(1,2 \%)$. Сегодня считается, что до 5-6\% случаев НС могут возникать на фоне кортикальных мальформаций [2], которые чаще всего представлены туберозным склерозом, фокальной кортикальной дисплазией, гемимегалэнцефалией, лиссэнцефалией, субкортикальной ламинарной гетеротопией, перивентрикулярной узловой гетеротопией, шизэнцефалией и полимикроги- 
рией. НС при значительных структурных аномалиях мозга могут иметь ранний дебют (внутриутробно или в первые минуты/часы после рождения), отличаться полиморфизмом. НС в таких случаях предшествуют развитию эпилепсии, часто характеризующейся резистентностью к лечению.

Достижением последних лет стало раскрытие генетических механизмов ряда церебральных дисгенезий. При этом показано, что различные клинические состояния могут быть связаны с общей молекулярно-генетической основой. Недавно установлено, что мегалэнцефалия, гемимегалэнцефалия, фокальная кортикальная дисплазия типа IIb и комплекс туберозного склероза могут представлять собой близкие патологические состояния, сопровождающиеся избыточным ростом мозговой ткани в результате мутаций, вызывающих изменения на разных этапах внутриклеточного сигнального пути PI3K-AKT-mTOR [5, 14]. Эти заболевания могут манифестировать с НС и сопровождаться резистентной к лечению эпилепсией. Между тем, результаты генетической диагностики делают возможным применение патогенетической терапии - ингибиторов mTOR (например, эверолимуса).

Клиническое и инструментальное обследование нашей когорты пациентов в неонатальном периоде и последующее катамнестическое наблюдение за ними не выявило указаний на наличие у них таких моногенных заболеваний, как доброкачественная семейная неонатальная эпилепсия и эпилептические энцефалопатии с дебютом в неонатальном периоде. Тем не менее, при обследовании детей с НС следует учитывать вероятность данных состояний, прежде всего при отсутствии очевидных причин раннего поражения ЦНС. Это особенно важно поскольку в настоящее время возрастают возможности таргетной терапии у детей с эпилептическими синдромами генетической природы. В связи с этим важное значение приобретает раннее проведение генетической диагностики $[5,15]$.

Доброкачественная семейная неонатальная эпилепсия (ДСНЭ) - редкое заболевание с аутосомно-доминантным типом наследования и неполной пенетрантностью. Прогноз в отноше- нии нервно-психического развития - благоприятный. Приступы в виде серий возникают в первые дни жизни, бывают асимметричными тоническими с переходом в односторонние или асинхронные двусторонние клонии, часто сопровождаются апноэ и десатурацией. Период персистирования приступов составляет от 3-5 дней до нескольких недель. Идентифицированы два генетических локуса ДСНЭ, которые кодируют потенциал-зависимые калиевые каналы: KCNQ2 в 20q13.3 и KCNQ3 в 8q24 [16].

Новая проблема, которая обсуждается в отношении генетических эпилепсий и особенно каналопатий, связана с тем, что мутации одних и тех же генов могут детерминировать как доброкачественные, так и тяжелые формы эпилепсии. Типичным примером такого рода служит KCNQ2, с которым связано большинство случаев ДСНЭ. Установлено, что мутации de novo KCNQ2 лежат в основе существенного числа случаев ранней эпилептической энцефалопатии [5], характеризующейся тяжелым течением и частыми приступами, сходными по семиологии с таковыми при ДСНЭ. В отличие от ДСНЭ при эпилептической энцефалопатии KCNQ2 клинически отмечаются мышечная гипотония, бедность спонтанных движений, отсутствие фиксации взора, снижение реактивности, на интериктальной ЭЭГ до назначения антиконвульсантов - мультифокальные изменения. По-видимому, de novo мутации KCNQ2 приводят к более значительным изменениям функций калиевых каналов [5]. Если сопоставить эти факты с описанием неблагоприятных исходов в некоторых семьях с ДСНЭ с мутациями KCNQ2 и KCNQ3, а также с недавно уточненными показателями риска развития эпилепсии у пациентов с ДСНЭ, который достигает $25 \%$ [17] (что гораздо выше ранее предполагавшихся значений), представляется весьма вероятным, что ДСНЭ и эпилептическая энцефалопатия KCNQ2 входят в фенотипический спектр, который детерминируется генотипом, но одновременно модифицируется генетическим фоном (генами-модификаторами). В отношении патогенетической терапии предлагается применение блокаторов калиевых каналов, в частности карбамазепина и ретигабина [5]. 
Сходство с симптоматическими НС может отмечаться в случаях дебюта в неонатальном периоде ряда эпилептических энцефалопатий: синдрома Отахара (ранняя младенческая эпилептическая энцефалопатия), ранней миоклонической энцефалопатии, синдроме КопполаДюлака (злокачественных мигрирующих парциальных приступах младенчества). При этом судороги обычно начинаются в первые 10 дней жизни и могут наблюдаться уже вскоре после рождения. В дальнейшем формируются глубокое отставание в психомоторном развитии, стойкие неврологические нарушения и эпилептические приступы, резистентные к терапии.

В патогенезе ранней (неонатальной) миоклонической энцефалопатии могут играть роль врожденные нейрометаболические нарушения: некетогенная гиперглицинемия, пропионовая ацидурия, D-глициновая ацидемия, метилмалоновая ацидемия, болезнь Менкеса [6, 18]. Основной тип приступов (обычно дебютируют в первые три месяцы жизни) - миоклонические, преимущественно в форме фрагментарного эпилептического миоклонуса. Возможно появление генерализованного миоклонуса, коротких частых, серийных приступов, тонических спазмов. Типичны статусное течение приступов, глубокое отставание в психомоторном развитии. При нейровизуализации обычно обнаруживаются только признаки нарастающей корковой атрофии. На ЭЭГ выявляется паттерн «вспышкаподавление» (с периодами угнетения до 4-12 сек), особенно выраженный при записи во время сна. Через 3-4 месяца от времени дебюта возможна трансформация этого паттерна в модифицированную гипсаритмию или мультифокусные спайки. Заболевание имеет неблагоприятный прогноз, приступы отличаются резистентностью к терапии, большинство пациентов погибают в возрасте до 2-х лет.

Синдром Отахара (ранняя младенческая эпилептическая энцефалопатия с паттерном «вспышка-подавление» на ЭЭГ) дебютирует в возрасте до 3-х мес., чаще - на 1-м месяце жизни. Основной тип приступов представлен тоническими спазмами продолжительностью до 10 сек., которые обычно возникают в виде серий (до 10-40 спазмов в серию) и отмечаются как в период бодрствования, так и во сне. Могут наблюдаться короткие парциальные приступы, в основном - гемиконвульсивные. По данным S.Ohtahara [19], миоклонических приступов при данном синдроме быть не должно, а если они имеются, то, вероятнее всего, являются манифестацией ранней миоклонической энцефалопатии. Для этих приступов характерно резистентность к терапии и неблагоприятный прогноз. На ЭЭГ во время бодрствования и сна выявляется паттерн «вспышка-подавление», который к возрасту 6 мес. обычно сменяется модифицированными вариантами гипсаритмии, но при наличии грубых структурных дефектов ЦНС может сохраняться дольше.

По данным самого S.Ohtahara данный синдром полиэтиологичен, но в большинстве случаев имеется пренатальное поражение; структурные изменения встречаются в 85\% случаев, которые часто бывают асимметричными [19]. Недавно установлено, что в основе синдрома Отахара могут лежать кортикальные мальформации и различные генные мутации. Генетические изменения оказались неоднородными - обнаружено вовлечение гена ARX (фактор транскрипции - кодирует белок, регулирующий деятельность других генов и развитие структур переднего мозга) и гена STXBP1 (синтаксин-связывающий белок, регулирует функцию синаптических везикул), при изменениях которых может развиваться как синдром Отахара, так и другие варианты клинического и эпилептического фенотипа [5, 14]. У других пациентов с картиной синдрома Отахара были выявлены мутации KCNQ2, CDKL5, KCNT1 [14].

Получены результаты генетических исследований при синдроме Коппола-Дюлака или злокачественных мигрирующих парциальных приступах младенчества (ЗМППМ). Эта редкая форма эпилептической энцефалопатии младенческого возраста характеризуется дебютом в первые 6 мес. жизни, множественными, практически непрерывными мигрирующими мультифокальными приступными паттернами с вовлечением различных отделов обоих больших полушарий мозга, отставанием психомоторного развития, резистентностью к терапии антикон- 
вульсантами и неблагоприятным прогнозом [20]. Довольно часто причиной ЗМППМ служит мутация de novo в гене KCNT1 в локусе 9q34.3 (с усилением функции), кодирующего работу активируемых натрием калиевых каналов [14]. В исследованиях in vitro [21], а затем в клинических наблюдениях у пациентов с ЗМППМ [22] продемонстрирована эффективность антиаритмического и противомалярийного препарата хинидин, который значительно уменьшал эффект «усиления функции» при мутации KCNT1 и снижал частоту приступов.

В качестве другого примера индивидуализированной терапии можно привести выраженный позитивный эффект леветирацетама у пациентов с ранней младенческой эпилептической энцефалопатией, обусловленной гетерозиготной мутацией гена STXBP1 в 9q34.11 [23, 24, 25]. Заболевание проявляется НС с последующим глубоким отставанием в психомоторном развитии, эпилепсией (в том числе синдромом Отахара), экстрапирамидными расстройствами. Так, благодаря леветирацетаму, удалось достичь стойкой клинико-электроэнцефалографической ремиссии эпилепсии с фармакорезистентным течением у мальчика в возрасте 1 месяца с возникшей de novo мутацией STXBP1 [24]. Терапевтический эффект леветирацетама у этих пациентов вероятно связан с уникальным механизмом действия: связывание с гликопротеином синаптических везикул SV2A и регуляция динамики выброса нейромедиаторов в синаптическую щель приводят к снижению эпилептической активности нейронов. Высокая эффективность леветирацетама подтверждена на выведенной линии эпилептических мышей с мутацией гена STXBP1 [26].

Представляется перспективным дальнейшее изучение молекулярно-генетических механизмов НС и эпилепсий с ранним дебютом. Результаты этих исследований позволяют рассчитывать на индивидуализацию терапевтических подходов. Идентификация специфических генных мутаций может иметь существенное значение для ранней постановки диагноза, выбора оптимальной терапии и исключения ненужных назначений.

Следует отметить, что леветирацетам привле- кает к себе значительное внимание, как средство терапии НС (в настоящее время данное показание для препарата официально не зарегистрировано, он разрешен к применению с возраста 1 мес.). К препаратам первой линии в лечении НС относятся фенобарбитал, фенитоин и бензодиазепины, а леветирацетам включен в число лекарственных средств второй линии $[1,2]$. Преимуществами леветирацетама считаются низкая частота побочных эффектов, отсутствие межлекарственных взаимодействий и неблагоприятного влияния на дальнейшее развитие ЦНС, а также доступность форм для внутривенного и перорального введения [2]. Кроме того, леветирацетам характеризуется линейной фармакокинетикой, быстрой абсорбцией (в течение 30 мин), выведением не через печень, отсутствием связывания с протеинами плазмы $(<10 \%)$, относительно коротким периодом полужизни. Таким образом, фармакокинетика и профиль безопасности леветирацетама представляются более благоприятными, чем у традиционных средств терапии НС [2, 27].

В связи с общей незрелостью ЦНС и высокой частотой патологических факторов, неблагоприятно влияющих на развивающийся мозг, у недоношенных новорожденных значительно увеличена частота НС по сравнению с доношенными детьми. НС являются отражением повреждения ЦНС, которое в 40-60\% случаев обусловлено церебральной гипоксией-ишемией [2]. Повторяющиеся НС оказывают выраженное негативное влияние на развивающийся мозг даже без нарушений легочной вентиляции и церебральной перфузии за счет увеличения метаболических потребностей ЦНС, что приводит к высвобождению возбуждающих аминокислот, в частности глутамата [28]. НС непосредственно не вызывают гибели нейронов, но сопровождаются изменениями нейрогенеза и синаптической организации [29]. Поэтому продолжительные НС сопряжены с неблагоприятным прогнозом и могут приводить к формированию стойких нарушений двигательного и интеллектуального развития.

Важная проблема, которая остается предметом дискуссий, состоит во влиянии на развивающийся мозг как самих НС, так и противоэпилеп- 
тической терапии. НС - неотложные состояния, требующие быстрого лечения, поскольку судороги вызывают повреждения развивающегося мозга и, как следствие этого, приводят к развитию эпилепсии, нарушений психомоторного развития. Применяемые на современном этапе препараты первой линии в лечении НС (фенобарбитал, фенитоин и бензодиазепины) редко эффективны в предупреждении процессов эпилептогенеза и могут оказывать негативное влияние на познавательную активность детей [27, 30]. В экспериментах на животных показано, что леветирацетам обладает свойствами нейропротектора и тормозит нейродегенеративные процессы на моделях гипоксии-ишемии [31] и эпилепсии [32]. Литвинова С.А. и соавт. [33] изучали эффекты леветирацетама на начальной стадии развития эпилептической системы (ЭС) у крыс с кобальтовой эпилепсией, при этом значительное подавление пароксизмальной активности во всех исследуемых структурах мозга наблюдалось при введении леветирацетама в дозе 200 мг/кг на 6-й день развития ЭС. Наибольшая выраженность противосудорожного эффекта проявлялась в гиппокампограммах, что выражалось в нормализации биоэлектрической активности и появлении регулярного тетаритма. По данным этих исследований эффекты леветирацетама в большей степени направлены на гиппокампальные очаги эпилептиформной активности и в меньшей степени на корковые очаги [33].

За последнее десятилетие накоплены многочисленные клинические наблюдения и проведен ряд открытых исследований эффективности леветирацетама в терапии НС различной этиологии при его назначении после того, как не удалось добиться результатов при применении пре-

\section{ЛИТЕРАТУРА - REFERENCES - ӘDӘВIYYYAT}

1. Гузева В.И., Заваденко А.Н., Медведев М.И., Дегтярева М.Г., Холин А.А. Неонатальные судороги. В кн.: Федеральное руководство по детской неврологии. Под ред. В.И. Гузевой. М.: МК, 2016, с. 155-168

2. Baumer F.M., Wusthoff C.J. Neonatal seizures: evaluation, treatment and prognosis. In: Fetal and neonatal brain injury. Eds. Stevenson D.K., Benitz W.E., Sunshine Ph., Hintz S.R., Druzin M.L. 5th ed. Cambridge University Press, 2018, p. 655-681

3. Abend NS, Jensen FE, Inder TE, Volpe JJ. Neonatal паратов первой линии [27, 30, 34-40]. При этом удавалось снизить частоту НС на $50-80 \%$, что послужило основанием для проведения нескольких исследований эффективности леветирацетама в качестве препарата первой линии в терапии HC. В иссследовании Han et al. [27] продемонстрировали снижение числа НС за 24 часа у $57 \%$ (21 из 37) пациентов, среди которых были недоношенные новорожденные. Ramantani et al. [30] в проспективном исследовании достигли полного купирования НС у 30 (79\%) новорожденных, включая недоношенных, к концу 1-й недели применения леветирацетама.

Таким образом, проведенное исследование подтвердило, что значительную роль в генезе НC играют перинатальные гипоксически-ишемические $(72,1 \%)$ и гипоксически-геморрагические поражения ЦНС (6,1\%), при этом ПИВК III-IV ст. отмечались только у недоношенных детей с ГВ до 32 нед. Среди доношенных новорожденных возрастала роль нейроинфекций $(23,5 \%)$. Частота редких этиологических факторов НС, прежде всего - генетических заболеваний, не зависела от ГВ пациентов. К особенностям клинических проявлений НС следует отнести их полиморфизм, преобладание атипичных приступов у детей с меньшим сроком гестации. Тонические НС чаще регистрировались у более зрелых новорожденных с ГВ 33 нед. и более. Среди детей первых месяцев жизни, перенесших НС, необходимо выделять группу риска по формированию эпилепсии. В качестве предикторов эпилепсии следует рассматривать фокальность, высокую частоту, более поздний дебют приступов, их серийный или статусный характер, обнаружение структурных повреждений ЦНС и неблагоприятных в прогностическом отношении ЭЭГ-паттернов.

seizures. In: Volpe's Neurology of the newborn. Eds. Volpe JJ, Inder TE, Darras BT, de Vries LS, du Plessis AJ, Neil JJ, Perlman JM. Elsevier, 2018, p. 275-324

4. Vasudevan C, Levene M. Epidemiology and aetiology of neonatal seizures // Semin Fetal Neonatal Med. 2013; 18(4): 185-191 DOI: 10.1016/j.siny.2013.05.008

5. Sands TT, McDonough TL. Recent Advances in Neonatal Seizures // Curr Neurol Neurosci Rep 2016; 16(10): 92 DOI 10.1007/s11910-016-0694-х

6. Айкарди Ж., Бакс М., Гиллберг К. Заболевания нервной системы у детей. Пер. с англ.; под ред. А.А. Скоромца. - 
М.: БИНОМ, 2013.-1036 с.

7. Pisani F, Spagnoli C. Neonatal seizures: a review of outcomes and outcome predictors // Neuropediatrics. 2016; 47(1): 12-19 DOI: http://dx.doi.org/10.1055/s-0035-1567873 8. Pisani F, Facini C, Pavlidis E, Spagnoli C, Boylan G. Epilepsy after neonatal seizures: literature review // Eur J Paediatr Neurol. 2015; 19: 6-14 DOI: 10.1016/j.ejpn.2014 9. Заваденко А.Н., Дегтярева М.Г., Медведев М.И., Рогаткин С.О., Гребенникова О.В. Динамическое клинико-нейрофизиологическое наблюдение детей различного гестационного возраста с неонатальными судорогами // Педиатрия. Журнал им. Г.Н. Сперанского. 2017; 96(1): c.23-28.

10. Заваденко А.Н. Неврологические исходы и особенности становления биоэлектрической активности головного мозга у детей различного гестационного возраста с неонатальными судорогами Автореферат дисс. кандидата мед. наук. М., 2014, 26 c.

11. Буркова А.С., Володин Н.Н., Журба Л.Т., Медведев М.И., Рогаткин С.О., Тимонина О.В. Классификация перинатальных поражений нервной системы и их последствий у детей первого года жизни (методические рекомендации Российской Ассоциации специалистов перинатальной медицины) // Вопросы практической педиатрии. 2006 , 1(2): c.38-70.

12. Строганова Т.А., Дегтярева М.Г., Володин Н.Н. Электроэнцефалография в неонатологии. М.: ГЭОТАРМЕД, 2005, $277 \mathrm{c}$.

13. Дегтярева М.Г., Рогаткин С.О., Ворон О.А., Володин Н.Н. Экспертная оценка ЭЭГ физиологического сна у недоношенных детей различного гестационного возраста с перинатальными поражениями ЦНС // Вопросы практической педиатрии. 2006, 5(1): 5-13.

14. Mirzaa GM, Poduri A. Megalencephaly and hemimegalencephaly: breakthroughs in molecular etiology // Am J Med Genet C: Semin Med Genet. 2014; 166C(2): 156-172 DOI: 10.1002/ajmg.c.31401

15. Pisani F, Percesepe A, Spagnoli C. Genetic diagnosis in neonatal-onset epilepsies: back to the future // European journal of paediatric neurology 2018; 22(2): 354-357 DOI: 10.1016/j.ejpn.2018.02.006

16. Plouin P., Neubauer B.A. Benign familial and non-familial neonatal seizures. In: Epileptic Syndromes in Infancy, Childhood and Adolescence. - Eds.: M. Bureau, P. Genton, C. Dravet, A.V. Delgado-Escueta, C.A. Tassinari, P. Thomas, P. Wolf. 5th ed. - Montrouge, France: John Libbey \& Co., 2012, p. $77-88$

17. Grinton BE, Heron SE, Pelekanos JT, Zuberi SM, et al. Familial neonatal seizures in 36 families: clinical and genetic features correlate with outcome // Epilepsia. 2015; 56(7): 1071-1080 DOI: 10.1111/epi.13020

18. Холин А.А. Эпилептический статус в младенческом и раннем детском возрасте. Автореферат дисс. доктора мед. наук. М., 2010, 54 c.

19. Ohtahara S., Ohtsuka Y., Oka E. Epileptic encephalopathies in early infancy // Ind. J. Pediatr. 1997; 64: 603-612

20. Холин А.А. Злокачественные мигрирующие парциаль- ные приступы младенчества или синдром КопполаДюлака // Журнал неврологии и психиатрии им. С.С.Корсакова. 2013; 113(3): 21-27

21. Milligan CJ, Li M, Gazina EV, Heron SE, et al. KCNT1 gain of function in 2 epilepsy phenotypes is reversed by quinidine // Ann Neurol. 2014; 75(4): 581-590 DOI: 10.1002/ana. 24128

22. Bearden D, Strong A, Ehnot J, DiGiovineM, Dlugos D, Goldberg EM. Targeted treatment of migrating partial seizures of infancy with quinidine // Ann Neurol. 2014; 76(3): 457-461 DOI: $10.1002 /$ ana. 24229

23. Stamberger H, Nikanorova M, Willemsen MH, Accorsi P, et al. STXBP1 encephalopathy: A neurodevelopmental disorder including epilepsy // Neurology 2016; 86(10): $954-962$ DOI: $10.1212 /$ WNL.0000000000002457

24. Dilena R, Striano P, Traverso M, Viri M, Cristofori G, Tadini L, Barbieri S, Romeo A, Zara F. Dramatic effect of levetiracetam in early-onset epileptic encephalopathy due to STXBP1 mutation // Brain Dev. 2016; 38(1): 128-131 DOI: 10.1016/j.braindev.2015.07.002

25. Liu S, Wang L, Cai XT, Zhou H, Yu D, Wang Z. Therapeutic benefits of ACTH and levetiracetam in STXBP1 encephalopathy with a de novo mutation: A case report and literature review // Medicine (Baltimore). 2018; 97(18): e0663 DOI: 10.1097/MD.0000000000010663

26. Kovacevic J, Maroteaux G, Schut D, Loos M, et al. Protein instability, haploinsufficiency, and cortical hyper-excitability underlie STXBP1 encephalopathy // Brain. 2018; 141(5): 1350-1374 DOI: 10.1093/brain/awy046

27. Han JY, Moon CJ, Youn YA, Sung IK, Lee IG. Efficacy of levetiracetam for neonatal seizures in preterm infants // BMC Pediatrics 2018; 18(1):131 DOI: 10.1186/s12887-018-1103-1 28. Thibeault-Eybalin M-P, Lortie A, Carmant L. Neonatal seizures: do they damage the brain? // Pediatr Neurol. 2009; 40(3): 175-180 DOI: $10.1016 /$ j.pediatrneurol.2008.10.026

29. Holmes GL. Effects of seizures on brain development: lessons from the laboratory // Pediatr Neurol. 2005; 33(1): 1-11 DOI: $10.1016 /$ j.pediatrneurol.2004.12.003

30. Ramantani G, Ikonomidou C, Walter B, Rating D, Dinger J. Levetiracetam: safety and efficacy in neonatal seizures // Eur J Paediatr Neurol. 2011; 15(1): 1-7.

31. Hanon E, Klitgaard H. Neuroprotective properties of the novel antiepileptic drug levetiracetam in the rat middle cerebral artery occlusion model of focal cerebral ischemia // Seizure. 2001; 10(4): 287-93.

32. Marini H, Costa C, Passaniti M, Esposito M, Campo GM, Ientile R, Adamo EB, Marini R, Calabresi P, Altavilla D. Levetiracetam protects against kainic acid induced toxicity // Life Sci. 2004; 74(10): 1253-1264.

33. Литвинова С.А., Воронина Т.А., Неробкова Л.Н., Кутепова И.С., Авакян Г.Г., Авакян Г.Н. Особенности действия леветинола на развитие судорожной активности у крыс с кобальт-индуцированной хронической эпилепсией // Эпилепсия и пароксизмальные состояния. 2018; 10(1): 52-62 https://doi.org/10.17749/2077-8333.2018.10.1.052-062 34. Shoemaker M, Rotenberg J. Levetiracetam for the treatment of neonatal seizures // J Child Neurol. 2007; 22(1): 9598 https://doi.org/10.1177/0883073807299973 
35. Fürwentsches A, Bussmann C, Ramantani G, Ebinger F, Philippi H, Pöschl J, Schubert S, Rating D, Bast T. Levetiracetam in the treatment of neonatal seizures: a pilot study // Seizure. 2010; 19(3): 185-189 DOI: 10.1016/j.seizure.2010.01.003

36. Khan O, Cipriani C, Wright C, Crisp E, Kirmani B. Role of intravenous levetiracetam for acute seizure management in preterm neonates // Pediatr Neurol. 2013; 49(5): 340-343 DOI: $10.1016 /$ j.pediatrneurol.2013.05.008

37. Rakshasbhuvankar A, Rao S, Kohan R, Simmer K, Nagarajan L. Intravenous levetiracetam for treatment of neonatal seizures // J Clin Neurosci. 2013; 20(8): 1165-1167 DOI: 10.1016/j.jocn.2012.08.014
38. Shin JW, Jung YS, Park K, Lee SM, Eun HS, Park MS, Park KI, Namgung R. Experience and pharmacokinetics of Levetiracetam in Korean neonates with neonatal seizures // Korean journal of pediatrics. 2017; 60(2): 50-54 DOI: 10.3345/kjp.2017.60.2.50

39. Venkatesan C, Young S, Schapiro M, Thomas C. Levetiracetam for the treatment of seizures in neonatal hypoxic ischemic encephalopathy // J Child Neurol. 2017; 32(2): 210-214 DOI: $10.1177 / 0883073816678102$

40. Neininger MP, Ullmann M, Dahse AJ, Syrbe S, et al. Use of Levetiracetam in neonates in clinical practice: a retrospective study at a German university hospital // Neuropediatrics. 2015; 46(5): 329-334 DOI: 10.1055/s-0035-1558969

\title{
XÜLASə
}

\section{MÜXTəLİF HESTASION YAŞDA UŞAQLARDA NEONATAL QICOLMALAR}

\author{
Zavadenko A.N., Medvedyev M.İ., Deqtyareva M.Q., Roqatkin S.O., Zavadenko N.N. \\ Rusiya Sahiyya Nazirliyinin N.İ.Piroqov adina Rusiya Milli Tadqiqat Tibb Universiteti, Moskva, RF
}

Hestasion yaşdan (HY) asılı olaraq qruplara bölünmüş yenidoğulmuşlarda neonatal qıcolmaların (NQ) aparıcı etioloji amilləri tədqiq edilmiş edilmişdir: I - HY 28 həftə və daha az olan dərin vaxtından əvvəl doğulmuş 84 uşaq; II - HY 29-32 həftə olan 52 uşaq; III - HY 33-36 həftə olan 12 uşaq; IV - HY 37-41 həftə olan 17 vaxtında doğulan uşaq. Bütün 165 pasiyentin klinik-instrumental tədqiqatları NQ-1n aşağıdakı səbəblərini təyin etmişdir: 72,1\% serebral hipoksiya-işemiya; 6,1\% - III/IV dərəcə peri-intraventrikulyar qansızmalar (PIVQ); 9,7\% - mərkəzi sinir sisteminin (MSS) zədələnməsi ilə bətndaxili infeksiyalar; 9,7\% - neyroinfeksiyalar; 1,2\% - serebral disgeneziyalar; 1,2\% - genetik xəstəliklər. Bununla yanaşı III/IV dərəcə PIVQ NQ-1n səbəbi kimi HY 32 həftəyə qədər olan vaxtından əvvəl doğulanlarda qeydə alınmışdır. Vaxtında doğulanlarda neyroinfeksiyaların rolu artmışdır (23,5\%). NQ olan uşaqların müayinəsi zamanı, xüsusilə də MSS-nin erkən zədələnməsinin aşkar səbəbləri olmadıqda, genetik xəstəliklərin ehtimalını nəzərə almaq lazımdır. Bu ona görə vacibdir ki, müasir zamanda genetik təbiətli epileptik sindromalr zamanı target müalicənin imkanları artmaqdadır. NQ ilə uşaqlarda və epilepsiyanın erkən formalarında Levetirasetamın istifadə perspektivləri araşdırılmışdır.

Açar sözlər: neonatal qıcolmalar, vaxtından əvvəl doğulanlar, vaxtında doğulanlar, epilepsiya, epileptik ensefalopatiya, levetirasetam.

\section{SUMMARY}

\section{NEONATAL SEIZURES IN INFANTS OF DIFFERENT GESTATIONAL AGE}

\author{
Zavadenko A.N., Medvedev M.I., Degtyareva M.G., Rogatkin S.O., Zavadenko N.N. \\ N.I. Pirogov Russian National Research Medical University of the Russian Federation Ministry of \\ Health, Moscow, Russian Federation
}

Main etiologies of neonatal seizures (NS) were evaluated among 165 newborns of different gestational age (GA). Neonates suffered NS were subdivided into four groups: I - 84 early preterm newborns with GA 28 weeks and less, II - 52 with GA 29-32 weeks, III - 12 newborns with GA 33-36 weeks and IV - 17 term infants with GA between 37 and 41 wks. Complex clinical and instrumental assessment of 165 infants determined the following etiologies of NS: perinatal hypoxia-ischemia in $72.1 \%$ of cases, intracranial hemorrhage grade III-IV in $6.1 \%$, congenital infections in $9.7 \%$, CNS infections (bacterial meningitis and viral meningoencephalitis) in 9.7\%, cerebral dysgenesis in 
$1.2 \%$ and inborn errors of metabolism and neurodegenerative diseases accounted for $1.2 \%$. Intracranial hemorrhage grade III-IV was only registered in newborns with GA less than 32 wks. The role of CNS infections increased in term newborns (23.5\%). Possibility of genetic etiologies should be taken into consideration while investigating newborns with NS, mainly when the possible early brain damage causes are absent. This is of great importance because the potentials of targeted therapies for epileptic syndromes due to genetic conditions are increasing nowadays. Perspectives of levetiracetam use in infants with NS and early onset forms of epilepsy were discussed.

Keywords: neonatal seizures, preterm newborns, term newborns, epilepsy, epileptic encephalopathies, levetiracetam.

Redaksiyaya daxil olub: 12.07 .2018

Çapa tövsiya olunub: 09.08.2018

Rayçi: professor Mammadbayli A.K. 